\title{
Mechanization in Chaff Cutting Phenomenon - A Review
}

\author{
Pooja Khobragade ${ }^{1}$, Aditya Manwatkar ${ }^{2}$, Pravin Khope ${ }^{3}$, Subhash Waghmare ${ }^{4}$ \\ 1,2,3,4 Mechanical Engineering Department, Priyadarshini College of Engineering, Nagpur - India.
}

\begin{abstract}
The livestock sector is crucial in the Indian economy and provides supplementary income for many resource-poor people. Livestock rearing in society, whether in the rural or urban setting, assures healthy and nutritious diets, and at the national and regional levels, it provides people with inexpensive, nutritious, and safe animal-sourced food. The majority of the fodder demand is satisfied by feeding agricultural leftovers and grazing area. India grows a lot of fodder crops. The fodder crop and livestock sectors in India are inextricably linked. Fodder production all year is critical for profitable and sustainable cow ranching. The feeding of green fodder to dairy animals is critical to the long-term viability of dairy production. However, in the current scenario, the supply of livestock feed is insufficient to satisfy demand, and it is critical to improve the availability of feed resources. As a result, machines and their sizes are necessary in Indian conditions to meet their demands. Forage crop production and usage are labor-intensive, which raises the overall cost of cultivation. This necessitates adequate automation in feed production and usage. Farm mechanization in India is about 40-45 percent, which is relatively low when compared to nations such as the United States, Brazil, and China. Mechanization promotes the efficiency of large-scale production, which eventually leads to urbanization and commercialization in the agricultural sector.
\end{abstract}

.Keywords- Mechanization, Chaff cutter, Fodder Cutter

\section{I- INTRODUCTION}

L Livestock production is the lifeblood of Indian agriculture, accounting for 4.11 percent of national GDP and 24.60 percent of agricultural GDP (GOI, 2017). The livestock sector employs about 1.10 billion people and provides a living for one billion of the world's poorest people [1]. A significant portion of animal production is reliant on forage-based systems. Different feed crops are utilized throughout India's various climate, but the area under farmed fodder is stalling at approximately 8.5 million hectares, owing to the human population's demand for food and other income crops [2]. Animal productivity is $20-60 \%$ lower than the world norm due to poor feeding, poor health care, and poor management [3]-[4]. With only 2.29 percent of the world's surface area, India is home to almost 17.4 percent of the world's human population and 10.7 percent of the world's cattle (more than 510 million head), putting a strain on land, water, and other resources. As acreage accessible for fodder production has decreased, cattle are putting great strain on available total feed and fodder. The country now has a net deficit of 35.60 percent green fodder, 10.95 percent dry agricultural wastes, and 44.00 percent concentrate feed components [5]-[6]. Feed and fodder 


\section{International Journal of Innovations in Engineering and Science, www.ijies.net}

shortages account for half of the overall loss, followed by breeding and reproductive issues $(21.1 \%)$, illnesses (17.9\%), and management $(10.5 \%)$. It is an urgent requirement to fulfill the demand of a rising number of livestock while simultaneously boosting their productivity, which necessitates an increase in the availability of feed supplies [7] - [8].

\section{II- NEED FOR MECHANIZATION IN THE PRODUCTION OF FODDER CROPS}

Fodder cultivation and usage include activities comparable to any other crop producing technique, such as seedbed preparation, crop sowing, weeding, harvesting, and so on [9]-[10]. Before feeding harvested fodder crop to animals, it is necessary to undertake preliminary processing. Fodder production, processing, and usage necessitate a significant amount of labour, as well as additional time and energy. Optimal forage crop production and use need minimal, essential, and timely operation [11]. Delays in the fodder production process frequently result in moisture loss and fast deterioration of fodder quality. Mechanization simplifies inter-cultural activities as well as sowing operations, which results in high-quality feed. Furthermore, healthy fodder is necessary to improve milk quality [12]. Mechanization is a necessary step in maintaining the health of cattle and their products.

\section{III- RESEARCH GAPS IN MECHANIZATION}

Cattle farms on grassland are a dynamic system that is challenging to manage, owing to their susceptibility to unpredictable environmental variables. Dheeraj and Manoranjan (2017) discovered a $0.87 \mathrm{hp}$ ha-1 use of farm power in terms of available machinery for farm operations, which was less than the claimed value of 1.5 hp ha-1 for effective farm operation through mechanization [13]. Agriculture automation is one of the most promising methods to meeting the rising need for population and land productivity.

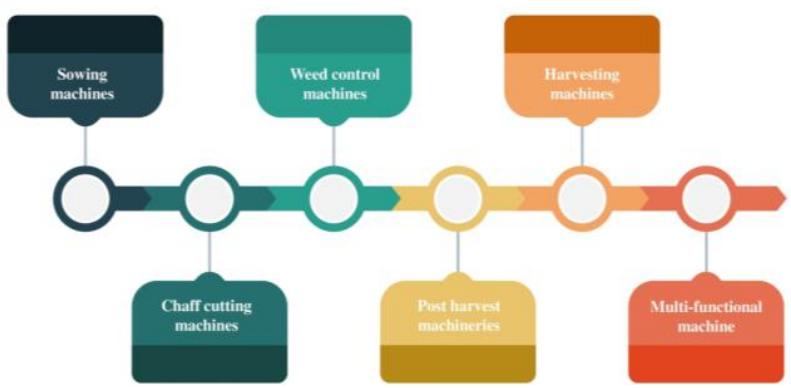

Fig 1-Machines available in fodder crop production

\section{IV- CHAFF CUTTING MACHINES}

Fodder-cutter machines are used by farmers in India to prepare fodder for their animals. When compared to hand cutting, the cost of operation and cutting time can be reduced by up to $70 \%$ when using fodder cutters [14].

\subsection{Manual chaff cutter}

A manual chaff cutter is made up of a feeding trough, cutting blades placed on a hollow flywheel, a cover plate, feed rollers, a shear plate, a handle, and a stand. The cutting edges are sharpened. Two people run the machine: one feeds the fodder or grass into the feeding trough and the other turns the flywheel using a handle [15]. The material supplied into the hopper is grabbed between the feed wheels, which pull it, and is chopped between the blades and the fixed shear plate. The length of the chopped material may be adjusted (16-32 mm). The equipment can readily cut both dry and green feed.

\subsection{Motorized chaff cutter}

An electric motor-powered chaff cutter is made up of a heavy-duty frame on wheels, a feeding chute, a conveyor chain, a chopping mechanism, a blowing mechanism, and a transmission mechanism. The unit has a selffeeding system with a feed reversal mechanism for further safety [16].

\subsection{Tractor operated movable chaff cutter}

Electrically operated chaff cutters are typically located in one location, and all chaffing materials are delivered to the chaffing yard. This is a time-consuming and laborious task. Labor and time may be saved if the chaff cutter is brought to the location where the material is heaped; a new generation tractor powered mobile type chaff cutters have been developed by ICAR-IGFRI, Jhansi. A tractor-driven portable chaff cutter is moved to the location where the chaffing material is stacked, and the chaffing is done there. The machine was used to chaff green fodder crops such as sorghum, maize, cowpea, napier-bajra hybrid grass, cenchrus grass, guinea grass, and hay fodder made from sorghum and cowpea. In the instance of Napier grass, a tractoroperated moveable chaff cutter was shown to be effective for chaffing fodder crops with stem thicknesses of up to $33 \mathrm{~mm}$. Freshly collected fodder chaffing efficiency was $100 \%$. In the case of dried hay material, it was $98.2 \%$ since the machine left dry sorghum leaves uncut in diameters ranging from 100 to $150 \mathrm{~mm}$ [17].

The chaff cutter cum grinder's performance in fodder crops was evaluated (maize and sorghum). The 


\section{International Journal of Innovations in Engineering and Science, www.ijies.net}

machine's production capacity for wet fodder was 272 kilogram $/ \mathrm{h}$ for maize, $330 \mathrm{~kg} / \mathrm{h}$ for sorghum, and for dry fodder $174.9 \mathrm{~kg} \mathrm{~h}-1$ for maize and $202.9 \mathrm{~kg} / \mathrm{h}$ for sorghum. The grinder's performance is $95 \mathrm{~kg} / \mathrm{h}$ for maize grains and $100 \mathrm{~kg} / \mathrm{h}$ for sorghum. The machine's chaffing efficiency for wet fodder was found to be 84.15 percent for maize and 86.5 percent for sorghum, while for dry fodder it was found to be 80.5 percent for maize and 86.3 percent for sorghum, and for the grinder it should be 96 percent and 95 percent for sorghum and maize grain, respectively. Based on these findings, the overall performance of the chaff cutter cum grinder was judged to be good, and it is appropriate for small and medium farms [18].

In the villages of northern India, fodder cutting machines are a major cause of serious accidents to adults and children. Among agricultural machine-related injuries, fodder cutter machines account for a sizable part of all injuries (Kumar et al., 2013). Adults are harmed when giving the fodder to the machine, whilst children are wounded while playing with the machine. In a community-based research in north India, Mohan et al (2004) discovered that all age groups experience foddercutter injuries when using the equipment. To prevent accidents, a comprehensive analysis of injuries and machine features allowed for the development of modest but effective technical interventions such as a warning roller, blade safety guard, gear cover, flywheel locking pin, and finger guard. These criteria have been integrated into the Bureau of Indian Standards, Manually Operated Fodder-Cutter Specification (BIS 7898), as well as a proposed standard on "Safety Requirements for Power Chaff Cutter."

Shredding stem fodder (hay, silage and haylage) is the main operation in the preparation of fodder mixtures for cattle. It was found that feeding cattle with chopped hay provides an increase in weight gain of $35 \%$, compared with feeding cattle with not chopped hay. A theoretical basis for the fineness adjustment of shredded stem fodder in open-type machines was developed to verify the reliability of the obtained analytical expressions [19]. Hassan (2019) performed a study to assess the performance of a small machine for chopping tubers of fodder beet, to establish the best machine operating parameters, and to select a product appropriate for creating good silage. The optimal operating parameters for the modified forage chopper machine are a cutter head speed of $23.5 \mathrm{~m} / \mathrm{s}$, a feed mechanism speed of 1.13 $\mathrm{m} / \mathrm{min}$, and a tubers moisture content of 74.4 percent when swinging knives are used.
Sarak et al. (2018) used a spring mechanism to replace the electric motor in a chaff cutting machine, which benefits farmers. The goal of this project was to run a machine that uses no fossil fuels and is powered entirely by human labour. It slices the feed consistently, which is great for cattle, and it is a long-lasting, low-maintenance equipment. In cylinder and flywheel type forage harvesters, the effects of theoretical length of cut, width of an open throat of a chopper unit, and entire stalk length on percent mass of particles in different diapasons by length were examined. When the relative mass of particles in the range of 8 to $19 \mathrm{~mm}$ by length is in the range of 45 to 75 percent, forage harvesters of this type produce high-quality forage chopping [20].

\section{V- CONCLUSION AND CHALLENGES OF MECHANIZATION}

The deployment of large capacity equipment through bespoke hiring services is a recent trend in farm mechanization. Because of the decrease in the number of draught animals, the usage of animal-operated equipment will diminish. However, the use of poweroperated tools will grow fast. As the leader in cow and buffalo population, and with livestock population rising at a pace of 1.23 percent per year, our country's present fodder output cannot match the demand. The agriculture and livestock industries in India are inextricably linked. The interconnections between these two sectors are so complicated that separating out the contributions from each sector would be impossible. Interactions between the crop and animal sectors have weakened over time, prompting mechanization of the majority of agricultural activities. The automation process in fodder crop production need quick growth and more study, since it has been an increasing issue for some years.

In general, for conventional farmers to accept contemporary technology there is a requirement to first improve on the present farming system in order to justify obtaining a better technology that would correspond to the features of their farming mode. Second, the technology transfer mechanism's appropriateness, accessibility, and cost must be acceptable.

\section{REFERENCES}

[1] Belkhode, P. N. (2019). Analysis and Interpretation of Steering Geometry of Automobile Using Artificial Neural Network Simulation. Engineering, 11(04), 231-239. doi:10.4236/eng.2019.114016. 


\section{International Journal of Innovations in Engineering and Science, www.ijies.net}

[2] Shelare, S. D., Aglawe, K. R., Waghmare, S. N., \& Belkhode, P. N. (2021). Advances in water sample collections with a drone - A review. Materials Today: Proceedings. doi:10.1016/j.matpr.2021.05.327.

[3] Dhutekar, P., Mehta, G., Modak, J., Shelare, S., \& Belkhode, P. (2021). Establishment of mathematical model for minimization of human energy in a plastic moulding operation. Materials Today: Proceedings. doi:10.1016/j.matpr.2021.05.330.

[4] Belkhode, P. N. (2019). Development of mathematical model and artificial neural network simulation to predict the performance of manual loading operation of underground mines. Journal of Materials Research and Technology, 8(2), 2309-2315. doi:10.1016/j.jmrt.2019.04.015

[5] Modak, J. P., Mehta, G. D., \& Belkhode, P. N. (2004). Computer Aided Dynamic Analysis of the Drive of a Chain Conveyor. Manufacturing Engineering and Materials Handling Engineering. doi:10.1115/imece200459157.

[6] Bejalwar, A., \& Belkhode, P. (2018). Analysis of Experimental Setup of a Small Solar Chimney Power Plant. Procedia Manufacturing, 20, 481-486. doi:10.1016/j.promfg.2018.02.071.

[7] Belkhode, P. N., Ganvir, V. N., Shende, A. C., \& Shelare, S. D. (2021). Utilization of waste transformer oil as a fuel in diesel engine. Materials Today: Proceedings. doi:10.1016/j.matpr.2021.02.008.

[8] Aglawe, K. R., Yadav, R. K., \& Thool, S. B. (2021). Preparation, applications and challenges of nanofluids in electronic cooling: A systematic review. Materials Today: Proceedings, $\quad 43, \quad 366-372$. doi:10.1016/j.matpr.2020.11.679.

[9] Waghmare S., Sirsat P., Sakhale C., Shelare S., Awatade S. (2017) A Case Study on Improvement of Plant Layout for Effective Production. International Journal of Mechanical and Production Engineering Research and Development, Volume 7, Issue 5, Oct 2017. Pp. 155-160.

[10] Waghmare S., Mungle N., Tembhurkar C., Shelare S., Sirsat P., Pathare N. (2019) Design and Analysis of Power Screw for Manhole Cover Lifter. International Journal of Recent Technology and Engineering, Volume 8, Issue 2, July 2019. Pp. 2782-2786, DOI: 10.35940/ijrte.B2628.078219.

[11] Mowade, S., Waghmare, S., Shelare, S., \& Tembhurkar, C. (2019). Mathematical Model for Convective Heat Transfer Coefficient During Solar Drying Process of Green Herbs. Computing in Engineering and Technology, 867-877. doi:10.1007/978-981-32-9515-5_81.
[12] Mathew, J. J., Sakhale, C. N., \& Shelare, S. D. (2020). Latest Trends in Sheet Metal Components and Its Processes-A Literature Review. Algorithms for Intelligent Systems, 565-574. doi:10.1007/978-981-150222-4_54.

[13] K. R. Aglawe, et al.,, K. R. A., et al.,. (2020). Geometric Analysis and Scope of Nanofluid in Micro Channel Heat Sinks for Electronic Cooling Application - A Review. International Journal of Mechanical and Production Engineering Research and Development, 10(3), 1244712468. doi:10.24247/ijmperdjun2020118.

[14] Dhande, H. K., S. D. Shelare, P. B. Khope. 2020. Developing a mixed solar drier for improved postharvest handling of food grains. Agricultural Engineering International: CIGR Journal, 22(4): 166-173.

[15] Jawalekar, S. B., and S. D. Shelare. 2020. Development and performance analysis of low cost combined harvester for rabicrops. Agricultural Engineering International:CIGR Journal, 22 (1):197-201.

[16] Waghmare S., Shelare S., Sirsat P., Pathare N, Awatade S. (2020) Development Of An Innovative Multi-Operational Furnace. International Journal of Scientific \& Technology Research Volume 9, Issue 04, April 2020. Pp 885-889.

[17] Shelare, S. D., Kumar, R., \& Khope, P. B. (2020). Formulation of a Mathematical Model for Quantity of Deshelled Nut in Charoli Nut Deshelling Machine. Advances in Metrology and Measurement of Engineering Surfaces, 89-97. doi:10.1007/978-981-15-5151-2_9.

[18] Waghmare, S. N., Shelare, S. D., Tembhurkar, C. K., \& Jawalekar, S. B. (2020). Development of a Model for the Number of Bends During Stirrup Making Process. Advances in Metrology and Measurement of Engineering Surfaces, 69-78. doi:10.1007/978-981-15-5151-2_7

[19] Shelare, S. D., Kumar, R., \& Khope P. B. (2021). Assessment of Physical, Frictional And Aerodynamic Properties of Charoli (Buchanania Lanzan Spreng) Nut As Potentials For Development Of Processing Machines. Carpathian Journal of Food Science and Technology, 174-191. doi:10.34302/crpjfst/2021.13.2.16.

[20] Waghmare, S. N., Sakhale, C. N., Tembhurkar, C. K., \& Shelare, S. D. (2019). Assessment of Average Resistive Torque for Human-Powered Stirrup Making Process. Computing in Engineering and Technology, 845-853. doi:10.1007/978-981-32-9515-5_79. 